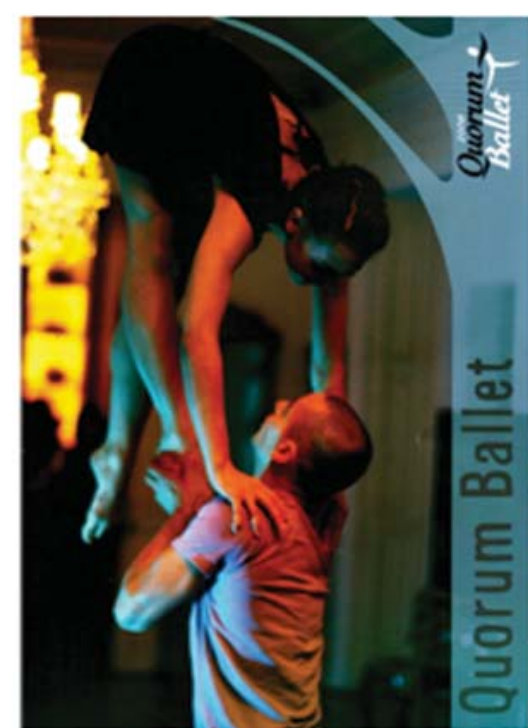

Dança contemporânea Quorum Ballet-Química. A ideia original e promoção da iniciativa são da autoria de Ana Paula Paiva, professora do Departamento de Química e Bioquímica da Faculdade de Ciências da Universidade de Lisboa (DQB-FCUL)

a água. Os alunos irão colocar os seus resultados sobre a qualidade e tratamento de água num mapa mundial usando a rede global, de forma a comparar resultados e contactar com outros colegas espalhados pelo globo. A experiência global é uma ini- ciativa da Comissão de Educação em Química da IUPAC. Inclui actualmente quatro actividades destinadas a cobrir conceitos químicos básicos mas capazes de despertar a curiosidade, com recurso a equipamentos simples. Pretende-se que os professores trabalhem com as suas turmas nas quatro actividades, dando aos estudantes uma visão geral de conceitos como acidez, salinidade, filtração e purificação de água. Esta experiência está a ser coordenada em Portugal pela Prof. Filomena Camões da FCUL, em colaboração com a SPQ.

Além destas actividades, a SPQ continuará com as suas acções e eventos regulares, de onde se destaca o XXII Encontro Nacional - 100 Anos de Química em Portugal. O evento decorrerá em Braga de 3 a 6 de JuIho, sob os auspícios da Delegação de Braga da SPQ, em colaboração com o Departamento de Química da Universidade do Minho, no Parque de Exposições de Braga. O encontro é organizado pelo Prof. João Paulo André (UMinho) e à semelhança dos encontros nacionais anteriores, inclui- rá a lição plenária do Prémio Ferreira da Silva, sendo igualmente atribuída a Medalha Vicente Seabra. Pela primeira vez será entregue o Prémio Romão Dias, no domínio da Química Inorgânica. Paralelamente, a Universidade do Minho tem também um programa específico para o AIQ 2011 onde se destaca uma exposição sobre Marie Curie, que estará patente durante o Encontro.

As celebrações do Ano Internacional da Química 2011 e do Centenário da SPQ são uma comemoração dos químicos portugueses. Os seus objectivos só podem ser atingidos com o envolvimento empenhado de todas as pessoas e instituições que se dedicam à investigação, ensino, aplicação e difusão da química em Portugal. A química faz parte da história colectiva do desenvolvimento da humanidade, daquilo que somos hoje e da forma como vivemos. O que seria de nós sem a química? Olhe à sua volta e tente identificar quais os objectos, seres ou materiais que poderiam existir sem que a química tivesse participado no processo da sua criação...

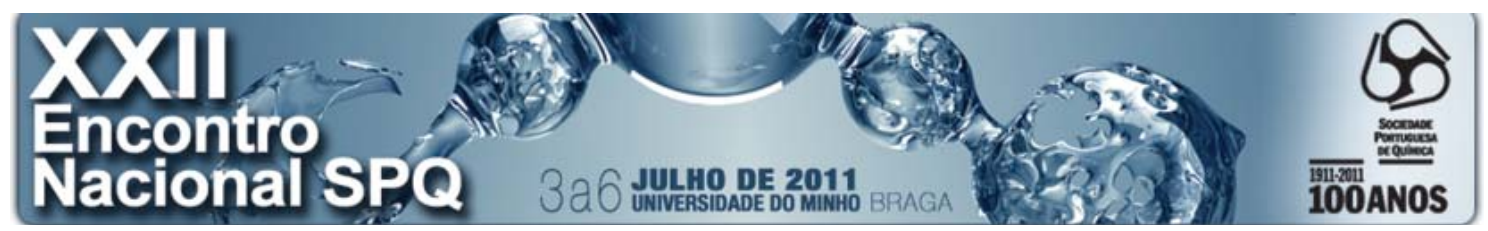

3 a 6 de Julho de 2011. "Cem Anos de Química em Portugal" será o tema do XXII Encontro Nacional, integrado não só nas comemorações do centenário da SPQ como também do Ano Internacional da Química

\title{
Actividades Planeadas Pelo Departamento de Química da Universidade do Minho no Âmbito do Ano Internacional da Química
}

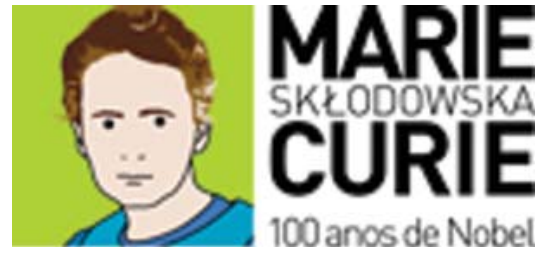

$\mathrm{O}$ ano em que se comemora o centenário da atribuição do Prémio Nobel da Química a Marie Curie, foi decretado pela UNESCO o Ano Internacional da Química (AIQ). Por uma feliz coincidência, 2011 é também o ano em que se comemora o centenário da SPQ.

Para assinalar estas efemérides, o Departamento de Química da UMinho projectou um conjunto de eventos e actividades em torno da personalida- de notável de Marie Curie, sob o título "A Beleza do Decaimento: Marie Curie e a História de um Nobel".

As comemorações do AIQ na UMinho tiveram início no dia 27 de Janeiro, numa cerimónia de lançamento que decorreu em simultâneo com a abertura oficial do AIQ na UNESCO, em Paris. A abertura foi oficializada através de uma conferência de imprensa, seguindo-se duas palestras apresentadas pelo Prof. Miguel Castanho e pela Prof. $^{a}$ Raquel Gonçalves-Maia. Esta ocasião contou ainda com a apresentação do livro mais recente da Prof. ${ }^{a}$ Raquel Gonçalves-Maia, dedicado a Dorothy Hodgkin, uma das quatro muIheres até hoje laureadas com o Pré-

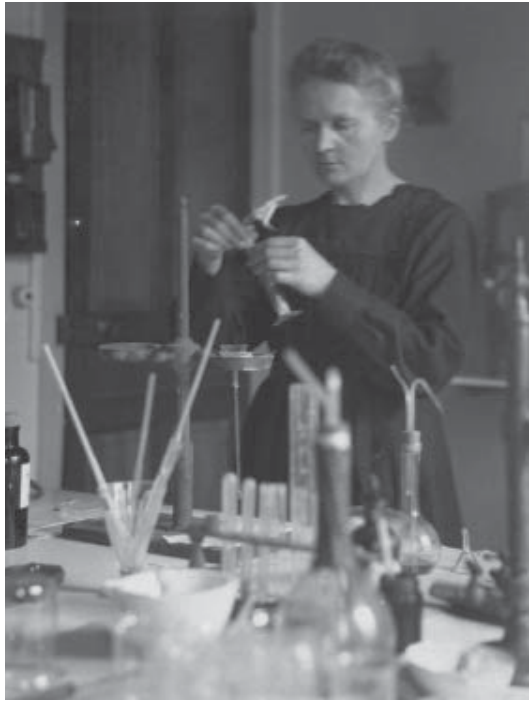

Madame Curie a trabalhar no seu laboratório (Imagem cedida pelo Museu Curie de Paris) 
mio Nobel da Química. O XXII Encontro Nacional da Sociedade Portuguesa de Química, que terá lugar no Parque de Exposições de Braga, de 3 a 6 de Julho de 2011, constituirá o ponto alto das comemorações. "Cem Anos de Química em Portugal" será o tema deste encontro, organizado pela Delegação de Braga da Sociedade Portuguesa de Química, em colaboração com o Departamento de Química da Universidade do Minho, integrado não só nas comemorações do centenário

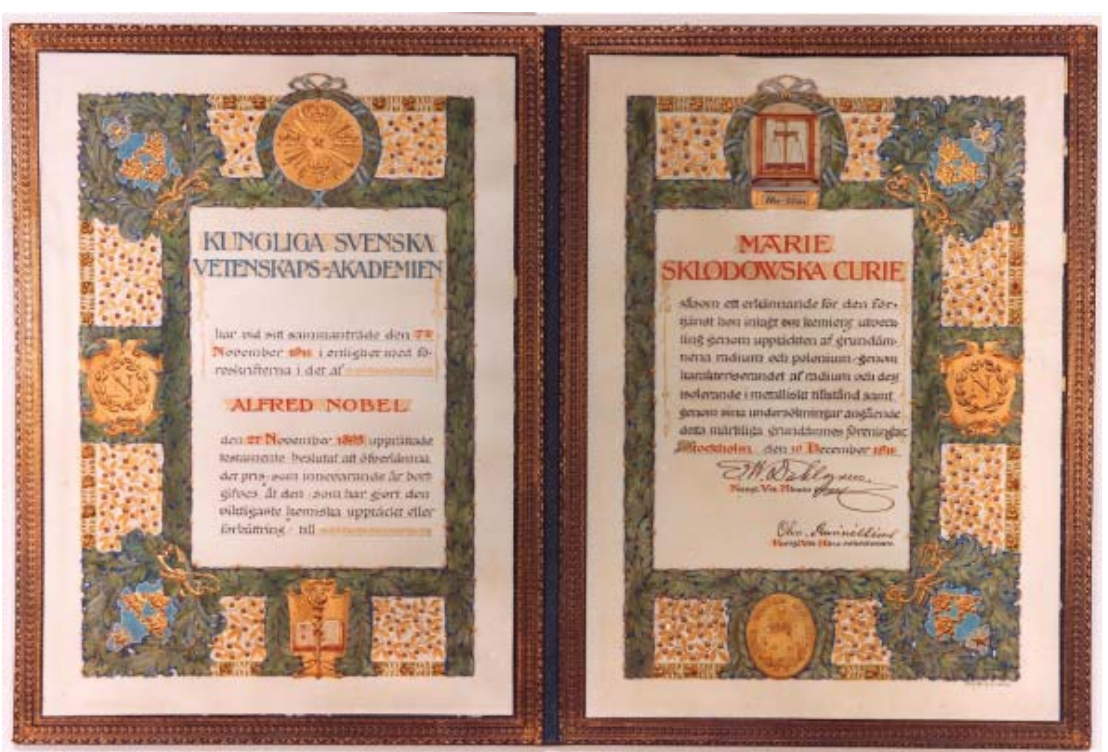

Diploma do Prémio Nobel atribuído a Marie Curie (Imagem cedida pelo Museu Curie de Paris) da SPQ como também do Ano Internacional da Química.

Ao longo do ano estão previstas diversas actividades, entre as quais, palestras (os Professores Raquel Gonçalves-Maia, Décio Martins e Jorge Calado já confirmaram a sua disponibilidade), exposições, homenagens aos discípulos portugueses de Marie Curie (Branca Edmée Marques, Mário Silva e Manuel Valadares), momentos musicais, uma peça de teatro e a exibição

diversas actividades realizadas conjuntamente com a Escola Secundária Sá de Miranda, dando-se relevo às exposições: No Tempo de Marie Curie e o Túnel do Rádio, na qual se pretende recriar o laboratório dos Curie.

As actividades que constituem o programa contam com o apoio das seguintes instituições: Sociedade Portuguesa de Química, Ciência Viva, Reitoria da UMinho, Escola de Ciências da UMinho, Instituto Curie de Paris, Museu Curie de Varsóvia, Embaixada de França, Embaixada da Polónia, EDP, Fundação Calouste Gulbenkian e Braga Parque.

\section{João Paulo André}

(jandre@quimica.uminho.pt)

Presidente da Comissão Organizadora do XXII Encontro Nacional da SPQ

\section{Women Sharing a Chemical Moment in Time - Pequeno-Almoço / Almoço em Rede}

Dado que a celebração do Ano Internacional da Química se centra no ano do centenário da atribuição do Prémio Nobel a Madame Curie, e que neste ano também se pretende celebrar a mulher na Química, este iniciou-se, a nível global, com uma proposta de Mary Garson, professora de química na Universidade de Queensland, Brisbane, Austrália. Para tal propôs a realização de um pequeno-almoço, ainda antes da data da abertura oficial do ano internacional da química, no dia 18 de Janeiro, evento a que deu o título "Women sharing a chemical moment in time". Esta iniciativa realizouse em cerca de 100 locais espalhados por 44 países. Em Portugal, realizouse um pequeno-almoço dinamizado pelo Departamento de Química e Bioquímica da Faculdade de Ciências da Universidade de Lisboa e um almoço na Universidade de Aveiro. A partilha de um momento far-se-ia em todo o mundo ao longo de um período de cerca de $24 \mathrm{~h}$ que se iniciou em Wellington, na Nova Zelândia, e terminou no Hawaii, tendo os vários locais celebrado o acontecimento de formas diferentes. Se a maioria aderiu ao pequeno-almoço, outros houve que realizaram almoços e mesmo lanches e jantares.

Em Lisboa, um dos momentos-chave foi a ligação por Skype com a colega Elaine A. Moore, reunida com as químicas da Open University do Reino Unido, que comiam umas simples sandes à semelhança do nosso "Continental Breakfast", em vez do tradicional pequeno-almoço britânico (papas de aveia e ovos com bacon).

As promotoras de "Pequeno-almoço das Químicas" contaram com a pre- sença do Jornalista Vasco Trigo, director do Programa Com Ciência da RTP 2, transmitido às Quartas-feiras (disponível na Internet em ww1.rtp.pt/multimedia/progVideo.php?tvprog=26914), que, com uma equipa de filmagem, acompanhou as cerca de 2 horas do evento, tendo realizado uma pequena entrevista à organizadora, Prof ${ }^{a}$ Filomena Camões. Também a TVI passou em directo, no Jornal da hora do almoço, a entrevista que fez à Prof ${ }^{a}$ Filomena Camões e que foi divulgada na íntegra pelas Notícias da UL.

Foi uma reunião agradável, onde se começou por disponibilizar o vídeo e uma apresentação de diapositivos que foram facultados no sítio do AIQ 2011.

Um momento alto do programa foi a invocação da Prof. Branca Edmée Marques, aluna de Doutoramento de 